\title{
Do local para o nacional: o Orçamento Participativo (OP) e a institucionalização da participação popular ao longo da história do Partido dos Trabalhadores (PT)
}

Luciana Andressa Martins de Souza*

\section{Resumo}

Este artigo discute as relações entre OP e PT, nas arenas eleitoral e governamental, desde a formação do partido até a conquista do governo federal, visando contribuir com o debate mais recente sobre a dimensão política dessa instituição participativa (AVRITZER, 2009; DIAS, 2000; GOLDFRANK; SCHNEIDER, 2006; ROMÃ0, 2011; SOUZA, 2010, 2011, 2012, 2013a; WAMPLER, 2008 , 2011). Argumenta-se que, à medida que o PT se consolida como um dos mais importantes partidos da história política brasileira, a questão da institucionalização da participação popular vai se modificando no interior do conteúdo programático do partido, arrefecendose em função das exigências da competição política. Em suma, verifica-se que o OP foi um instrumento de consolidação do "modo petista de governar", que vai se modificando através do aprendizado da política (politics) e das políticas (policies) do local para o nacional.

\section{Palavras-chave}

Orçamento Participativo (OP). Partido dos Trabalhadores (PT). Competição política.

\section{Abstract}

This piece discusses the relationship between participatory budgeting and the Brazilian Workers' Party in electoral and governmental arenas, from the founding of the party to its victory in Brazilian federal elections. This research also aims to contribute to the most recent debate regarding the political dimension of this participatory institution (Avritzer 2009; DIAS 2000; Goldfrank \& SCHNEIDER, 2006; ROMÃ0, 2011; SOUZA, 2010, 2011, 2012, 2013a; Wampler, 2008, 2011). It has been argued that as the Workers' Party becomes one of the most important parties in Brazilian political history, the institutionalization of popular

\footnotetext{
* Pesquisadora e bolsista de Pós-Doutorado da Fundação de Amparo à Pesquisa de São Paulo (FAPESP) no âmbito do Centro Brasileiro de Análise e Planejamento (CEBRAP). E-mail: lu.ufscar@hotmail.com.
} 
participation has suffered from changes in the party's agenda, having weakened to meet the requirements of political competition. In short, it is clear that participatory budgeting, originally an instrument of consolidation concerning the party's "method of governance," is being remodeled nationally according to the party's political experience at the local level.

\section{Keywords}

Participatory budget. Brazilian workers party. Political competition.

\section{Introdução ${ }^{1}$}

Este artigo discute a importância do OP para o PT nas arenas eleitoral e governamental, desde a formação do partido até a conquista do governo federal. Não se trata de estabelecer uma relação causal entre a trajetória do OP e o crescimento eleitoral do PT, mas de iluminar hipóteses ainda pouco exploradas pela literatura ${ }^{2}$. Para tanto, verificam-se as mudanças no discurso petista em relação à questão da participação popular, ao longo do tempo, tendo em vista os dilemas enfrentados pelo partido e as estratégias utilizadas para conquista de espaço institucional. Argumenta-se que, à medida que o PT se consolida como um dos mais importantes partidos da história política brasileira, a questão da institucionalização da participação popular, que será focada especialmente através do OP, vai se modificando no interior do conteúdo programático do partido, arrefecendo-se em função das exigências da competição política.

A literatura sobre o OP vem se desenvolvendo nas últimas duas décadas e apresentando respostas mais realistas acerca do fenômeno em questão. Diversas análises produzidas tiveram como uma de suas dimensões centrais a preocupação com os interesses políticos que envolvem as relações entre

\footnotetext{
${ }^{1}$ Este artigo constitui uma versão revisitada do Capítulo 4 da minha tese de doutorado (2010). Versões preliminares deste texto foram apresentadas no II Fórum Brasileiro de Pós-Graduação em Ciência Política e no $8^{\circ}$ Encontro da Associação Brasileira de Ciência Política. Agradeço à FAPESP pela concessão da bolsa de pós-doutorado (Processo FAPESP 2012/21.434-6).

${ }^{2}$ Nessa relação há ainda uma desvantagem específica dos estudos sobre Instituições Participativas, chamada causalidade remota. "Uma causalidade remota é aquela em que a relação entre causa e efeito é atravessada por espaços longos de tempo e/ou mediada por uma sucessão ou encadeamento extenso de efeitos intermediários" (GURZA LAVALLE, 2011, p.41).
} 
essa instância participativa, os atores da sociedade civil, os partidos políticos (o PT em especial), o Executivo e o Legislativo, assim como as diferentes arenas nas quais essas relações se desenvolvem (AVRITZER, 2009; DIAS, 2000; GOLDFRANK; SCHNEIDER, 2006; ROMÃO, 2011; SOUZA, 2010, 2011, 2012, 2013a; WAMPLER, 2008, 2011).

Contudo, verifica-se que, apesar de o PT ser um dos protagonistas desse debate, não há um diálogo suficiente entre tais estudos e a literatura sobre partidos políticos ${ }^{3}$. Isso pode ser observado na concepção negativa dos partidos políticos como frágil, usualmente utilizada em detrimento de outra visão que examina os partidos brasileiros sob patamares mínimos de organização (MENEGUELLO, 1998) ${ }^{4}$. Outro aspecto é que esses trabalhos, em geral, avistam um PT solidificado. Entretanto, a literatura sobre o PT atenta para as progressivas mudanças nas estratégias políticas institucionais e eleitorais dessa legenda, ao longo do tempo, visando aumentar a sua inserção nas esferas estatais (MENEGUELLO, 1989; RIBEIRO, 2004, 2008, 2009; TELLES, 2009). Portanto, torna-se pertinente analisar as relações entre o OP e o PT para compreender melhor as relações entre os partidos políticos e as instituições participativas que vêm sendo incorporadas na estrutura governamental, como o OP.

Para entender a importância do OP para o PT, parte-se da ideia de desafios ambientais que provocam mutações em uma estrutura organizativa, desenvolvida por Panebianco $(2005)^{5}$, em seu estudo sobre o processo de transformação dos partidos, para explicar como as mudanças programáticas sofridas ao longo da trajetória petista impactaram na consolidação dessa instituição participativa. Aliado a essa perspectiva, utiliza-se como instrumento

\footnotetext{
${ }^{3} \mathrm{O}$ PT aparece nesse debate tanto como o partido que instituiu (embora haja controvérsias) e que mais difundiu o OP em suas administrações, como na discussão sobre o aparecimento da "comunidade política" (WAMPLER, 2011) e da importância da "sociedade política" (AVRITZER, 2009).

${ }^{4}$ Além disso, a negociação por cargos não é vista por meio do fisiologismo, mas como parte da lógica governamental, e pode significar altos graus de organização do sistema partidário (MENEGUELLO, 1998, p.36).

${ }^{5}$ Segundo o autor, a evolução organizativa de um partido depende do modelo originário e das pressões e desafios exercidos pelos ambientes nos quais a legenda atua. Assim, o processo de evolução organizativa implica a passagem de um momento inicial (construção da organização) para uma fase posterior (estabilização). Nas suas relações com o ambiente externo, o processo de institucionalização indica ainda a passagem de uma fase em que predomina uma estratégia agressiva de dominação do ambiente a outra, em que se sobrepõe uma estratégia de adaptação ao ambiente.
} 
analítico o argumento do institucionalismo histórico de path dependence $e^{6}$, para selecionar as sequências de eventos históricos que tiveram importância na questão da participação popular, ao longo da história do PT.

Os argumentos deste artigo foram desenvolvidos a partir da ampla bibliografia que se debruça sobre os estudos entre o OP e o $\mathrm{PT}^{7}$. Ademais, outras informações foram obtidas a partir dos seguintes sistemas oficiais de informações: Tribunal Superior Eleitoral (www.tse.gov.br), Instituto Brasileiro de Geografia e Estatística - IBGE (www.ibge.gov.br), Fundação SEADE - Sistema Estadual de Análise de Dados (www.seade.gov.br); além dos arquivos extraídos das "Resoluções de Encontros e Congressos: Partido dos Trabalhadores: 1979-1998”, obtidos no sítio da Fundação Perseu Abramo (www.fpabramo.org.br), e de outras documentos mais recentes obtidos no sítio do PT (www.pt.org.br).

$\mathrm{O}$ artigo está organizado como segue. Na primeira parte, examinam-se os principais dilemas enfrentados pelo PT nas primeiras disputas eleitorais e nas primeiras experiências de governos locais. A segunda parte se detém sobre os emblemáticos casos dos governos dos municípios de Porto Alegre e São Paulo. A terceira parte apresenta a difusão do "modo petista de governar" por meio do OP, assim como os diferentes deslocamentos produzidos por essa instância participativa. A penúltima parte faz um balanço das mudanças nas estratégias políticas utilizadas, pelo partido, para a conquista do governo federal e os seus possíveis impactos no OP. Por fim, a última parte recapitula os principais pontos abordados e aponta os principais desafios desta agenda de pesquisa.

\footnotetext{
${ }^{6}$ Path dependence: argumento amplamente utilizado pelos institucionalistas históricos, segundo o qual os indivíduos criam instituições que, por sua vez, constrangem as escolhas subsequentes desses indivíduos. Nesse sentido, eventos passados influenciam o presente, e a história conta (LEVI, 1997, p.28).

${ }^{7}$ Especialmente os seguintes estudos: Souza (2010, 2011, 2012 e 2013a); Baiocchi (2003b); Goldfrank (2003; 2006); Gurza Lavalle et al. (2004); Wampler (2008; 2010); Romão (2011); Avritzer (2009); Meneguello (1989; 2003); Ribeiro (2004; 2008; 2009); Couto (1995; 1998; 2003); Kowarick e Singer (1991), Dias (2000).
} 


\section{Da classe trabalhadora ao campo democrático popular: os principais dilemas enfrentados pelo PT nas primeiras disputas eleitorais e nas primeiras experiências de governos locais}

O PT se formou ao longo do processo de redemocratização como um expoente do movimento de greve dos trabalhadores da indústria do ABCD paulista, o qual se aliou a outros movimentos urbanos que lutavam pela expansão dos direitos sociais (movimento estudantil, movimento por moradia, etc.), além de segmentos progressistas da Igreja Católica (Comunidades Eclesiais de Base - CEBs), das diversas pastorais, de intelectuais de esquerda, de pequenos partidos clandestinos de tendência socialista e de segmentos da classe média que se uniram na constituição de um partido formado por um conjunto complexo de diferentes correntes (MENEGUELLO, 1989; KECK, 1991).

O PT, em seus primórdios, tinha um projeto político que proclamava a construção do socialismo no Brasil através da ampliação da participação política da classe trabalhadora e da chegada ao poder, objetivando a realização de uma política democrática e a construção de uma sociedade igualitária. Podemos verificar, por exemplo, no discurso do presidente Luís Inácio Lula da Silva, um dos fundadores do partido, na primeira convenção nacional do partido, o qual discorre sobre a construção de um socialismo novo, um "socialismo que queremos", que seria construído através da luta pela democracia e pelos direitos e autonomia dos trabalhadores.

O socialismo petista, dentro dessa perspectiva, objetivava a democratização da sociedade brasileira através da inclusão das classes marginalizadas à vida política, da implementação de políticas redistributivas e da criação de novos canais de participação popular, os quais ainda não estavam bem definidos.

Observa-se ainda que o PT, desde o início, incorporou um amplo espectro de posições distintas, as quais refletem uma estrutura aberta de tendências partidárias em oposição ao dirigismo vanguardista dos partidos tradicionais de esquerda. De certa forma, essas disputas internas entre as diferentes correntes contribuíram para o desenvolvimento de mecanismos democráticos na organização interna do partido ${ }^{8}$. Contudo, diversos exemplos posteriores,

\footnotetext{
${ }^{8}$ O PT tentou estabelecer estruturas para a participação das bases e procedimentos mais democráticos para as convenções do que os determinados pela legislação partidária (KECK, 1991). Atualmente, pode-se dizer que essas estruturas internas de participação nem sempre são respeitadas.
} 
como o governo da prefeita Luisa Erundina em São Paulo (1989-1992), podem mostrar que nem sempre foi fácil negociar a diversidade dessas posições ${ }^{9}$. Essas disputas levaram a ocasionais rachas, como em 1990, quando uma tendência de esquerda mais radical (a Causa Operária) se separou do partido.

Em 1982, o partido concorreu em 23 dos 25 Estados brasileiros, com a campanha intitulada "Trabalho, Terra e Liberdade" e o bordão "trabalhador vota em trabalhador", mas obteve resultados inferiores ao esperado pelo próprio partido. O PT atingiu menos de $3 \%$ dos votos, nacionalmente, mas comemorou resultados expressivos na região Sudeste e no movimento sindical, junto à classe trabalhadora (TELLES, 2009, p.118) ${ }^{10}$.

As primeiras prefeituras conquistadas, no início dos anos 1980, se defrontaram com inúmeros problemas oriundos de administrações públicas falidas, com uma máquina política ineficiente e, portanto, sem muita capacidade de investimentos frente às inúmeras demandas provenientes de setores marginalizados e das próprias bases petistas, por exemplo, o município de Diadema, localizado próximo ao parque industrial de São Paulo, o qual, além de ser uma das experiências administrativas precursoras do partido (1982-1985), constituiu-se uma das primeiras tentativas de instituir canais de participação no interior da administração petista. Segundo Baiocchi (2003b), a iniciativa de promover a participação popular por meio de conselhos deliberativos não obteve sucesso nessa primeira gestão do partido, devido ao baixo nível de organização das comunidades locais, somado ao fato de que os responsáveis por programas participativos confundiam o seu papel na administração com o de ativista político. Além disso, o autor assinala que os conflitos entre os órgãos dirigentes do PT local e a administração municipal sobre diretrizes gerais do governo bem como sobre outras políticas específicas enfraqueceram o quadro administrativo, a qual acabou não cumprindo com eficiência o seu plano de gestão.

Segundo Meneguello (1989), o fraco desempenho eleitoral do PT, nas eleições de 1982, "mostrou que o apelo classista e a idéia de inovação política, tônicas do discurso petista, não tiveram o alcance esperado pelo partido" (MENEGUELLO, 1989, p.195). De acordo com essa abordagem, esses

\footnotetext{
${ }^{9}$ Para uma maior aprofundamento desta questão, ver Couto (1995).

${ }^{10}$ Em 1982, o PT conquistou o governo dos municípios de Diadema (SP) e Santa Quitéria (MA), além de oito cadeiras no Congresso Nacional (TELLES, 2009).
} 
resultados evidenciaram que o discurso exageradamente classista restringiu a mensagem partidária a uma pequena parcela do eleitorado, deixando de lado outras fatias significativas, como a classe média.

Dessa forma, a autora verifica que o PT repensou as suas estratégias de atuação nas esferas político-institucional e político-eleitoral, visando ampliar a sua capacidade de representação, especialmente, entre os segmentos urbanos de classe média. Esse período de transição do partido, segundo a autora, pode ser dividido em dois momentos principais. O primeiro começa em 1982 e vai até 1985, quando o partido acaba se isolando politicamente, após a recusa em participar do Colégio Eleitoral que elegeu Tancredo Neves presidente da República ${ }^{11}$. A partir desse momento, o PT enfrentou uma grave crise interna em função desse firme posicionamento ${ }^{12}$, mas reforçou a sua imagem coerente perante a opinião pública, ao enfatizar o seu compromisso de ampliar a democratização do Brasil, redesenhando uma nova estratégia voltada para as futuras eleições (MENEGUELLO, 1989, p. 197-199).

Nas campanhas eleitorais de 1985 e 1986, o PT apresentou-se mais abertamente como uma alternativa distinta dos partidos existentes a amplos setores sociais, enfatizando tanto as questões mais gerais de cidadania e justiça social como os problemas locais. Isso impactou positivamente nos respectivos resultados eleitorais em relação às votações obtidas em 1982, mas, por outro lado, acentuou as divisões de grupos no interior do partido (MENEGUELLO, 1989, p.199-201; KECK, 1991, p.273).

Dentro dessa perspectiva, Fortaleza, a capital do Ceará, foi a segunda vitória eleitoral do PT, representando uma ruptura com as forças políticas tradicionais que se dividiram no poder durante um longo período. Segundo Castro (2008), embora a gestão da prefeita Maria Luiza Fontenelle não tenha produzido resultados concretos de gestão, em termos de efetivação de políticas públicas, ela introduziu importantes reformas nos serviços sociais e nos sistemas educacionais, além de programas de saúde inovadores. Segundo

\footnotetext{
${ }^{11}$ Em 1984, o PT se envolveu no movimento por eleições diretas para presidente da República, conforme resolução aprovada no $3^{\circ}$ Encontro Nacional, a qual inclui um forte posicionamento contra o Colégio Eleitoral.

12 "Posicionando-se contra o perigo do isolacionismo político, alguns de seus parlamentares opuseram-se à decisão oficial do partido e pagaram o risco de desobediência ao mandato imperativo. As saídas do líder do partido na Câmara Federal, deputado Airton Soares, e da deputada Bete Mendes causaram um impacto negativo na atuação institucional do PT, criticado por seu 'purismo' político" (MENEGUELLO, 1989, p.1999).
} 
o autor, a administração petista promoveu pouca participação e foi impedida de desenvolver muitos de seus programas devido aos constrangimentos fiscais e às rupturas internas ${ }^{13}$. Mesmo assim, a questão da participação a partir de canais institucionalizados, mesmo que não consolidada, representou o símbolo de um novo ciclo administrativo para o município.

Os anos seguintes foram marcados pelas atividades institucionais do partido na Assembleia Nacional Constituinte (ANG), em que o PT revelouse uma das agremiações políticas de perfil ideológico mais coerente. Essa imagem de coerência partidária e ideológica adicionada à grave crise econômica que assolava o país foi um ambiente propício para o partido superar as experiências negativas das prefeituras de Diadema (SP), em 1982, e Fortaleza (CE), em 1985, e desenvolver uma proposta de governo popular na campanha eleitoral de 1988 (MENEGUELLO, 1989, p. 201-202).

Em 1987, no "5ํ. Encontro Nacional", o PT aprovou uma série de resoluções políticas que compuseram a "estratégia democrática e popular", na qual a luta pela conquista do governo foi concebida como eixo articulador da estratégia de luta pelo socialismo no Brasil. Entre essas resoluções estava o "Programa Democrático-Popular", que abrangia interesses dos trabalhadores, e ainda uma "Política de Alianças do PT", também estratégica, abarcando alianças tanto no campo da classe trabalhadora como no campo democrático popular, corroborando a necessidade de novas parcerias eleitorais ${ }^{14}$.

As vitórias do PT, em grandes centros nas eleições municipais de 1988, traduziram "um importante momento no processo de consolidação do partido, qual seja, o da viabilização de sua proposta de governo popular, que vinha apontando desde as eleições de 1982 como uma novidade, e que desta vez conseguiu canalizar o desejo de mudança política por parte da população" (MENEGUELLO, 1989, p. 197). Por outro lado, "boa parte dos votos no PT nas eleições de 1988 e 1989 foi motivada por uma rejeição às elites políticas que haviam conduzido a transição para a democracia” (KECK, 1991, p.285),

\footnotetext{
${ }^{13}$ Cabe destacar que o PT criou, em 1988, o Departamento Nacional de Discussões de Ações Institucionais para coordenar planos de ações destinados às gestões municipais em virtude dos inúmeros conflitos enfrentados entre as primeiras administrações petistas e o próprio partido. Desse modo, quatro princípios constituíam a concepção petista municipal: participação popular, transparência, democratização do Estado e criação de nova cultura política.

${ }^{14}$ Resoluções referentes ao " $5^{\text {o․ }}$ Encontro Nacional" (ABRAMO, Fundação Perseu. Resoluções de Encontros e Congressos: Partido dos Trabalhadores: 1979-1998).
} 
o que não deixou de representar uma assertiva quanto à estratégia política do partido $^{15}$.

\section{A consolidação do "modo petista de governar": os governos dos municípios de São Paulo e Porto Alegre}

Entre as experiências participativas desenvolvidas pelo PT, no início dos anos 1990, a administração da prefeita Luisa Erundina, na capital paulista, e o governo que instituiu o OP, no município de Porto Alegre, foram as que mais se destacaram, tanto pela ampliação dos espaços participativos como pelo aprendizado produzido por essas duas gestões petistas. Ambas inauguraram um novo ciclo virtuoso para essa agremiação política, permitindo a continuidade e o aprofundamento daquilo que mais tarde foi coroado como o "modo petista de governar"16.

Agestão Luisa Erundina (1989-1992), no município de São Paulo, segundo Kowarick e Singer (1993, p. 216), “foi de vital importância para as várias redefinições programáticas do PT em âmbito nacional”. A administração Erundina, com a introdução de conselhos populares e outras tentativas de ampliar os canais de comunicação entre o governo e a população, representou um embrião das futuras concepções participativas do partido. Além disso, a postura negociadora adotada pelo partido, ao longo da sua gestão, não salvou o mesmo da sua derrota eleitoral, mas lhe rendeu a construção de políticas públicas que beneficiaram a população. Segundo Couto (1995), o Executivo municipal inicialmente optou por uma estratégia conflitiva, ou seja, pelo não estabelecimento de uma maioria parlamentar, tendo em vista o apoio dos movimentos sociais organizados, da opinião pública e dos futuros conselhos populares, como vislumbrava o "ethos petista"17. Mas, ao longo dessa gestão,

\footnotetext{
${ }^{15}$ Em 1988, o PT venceu em 38 municípios, incluindo importantes capitais como Porto Alegre e São Paulo (ABRAMO, TSE).

16 "O modo petista de governar vem dos anos 1980, quando o PT realizou seminários temáticos sobre experiências de governos municipais petistas. A sistematização dessas reflexões resultou na publicação de um livro cujo titulo expressava o conceito síntese formulado para abarcar essas experiências: O modo petista de governar, lançado em 1992" (BITTAR, 2003, p.15).

${ }^{17} \mathrm{O}$ ethos petista se refere ao modelo originário do partido: para maior aprofundamento desta questão ver: Couto (1995) e Menegello (1989), entre outros. No caso das relações entre o Executivo e o Legislativo, isso se restringia a construir coalizões com partidos dentro do mesmo espectro político (COUTO, 1998).
} 
o Executivo paulistano foi migrando para outra estratégia de negociação pontual, em virtude da necessidade de viabilizar a aprovação de políticas governamentais. Segundo Couto (1998, p. 64), essa transição revelou algo paradoxal, na medida em que os petistas incorporaram uma estratégia cooperativa na relação com o parlamento, reconhecendo a legitimidade da barganha alocativa ${ }^{18}$. Esse comportamento, na visão do autor, permitiu maior centralidade ao Poder Legislativo em virtude das negociações constantes com o Executivo, o que gerou enorme visibilidade, conferindo transparência ao processo decisório. O Executivo, por sua vez, também se beneficiou, embora tardiamente, dessa ruptura com o padrão patrimonial de interação entre os Poderes, através da viabilização de uma política de "inversão de prioridades", da recuperação tributária do município e da melhoria de serviços públicos (COUTO, 1998, p.65-69).

O governo de Porto Alegre, diferentemente da experiência paulistana, obteve mais sucesso em trazer os conflitos para serem resolvidos em arenas participativas. O PT, com a ajuda do OP, na capital gaúcha, segundo Baiocchi (2003b) e Dias (2000), encontrou caminhos para gerar consenso ao redor de plataformas redistributivas que ajudaram a prevenir conflitos contra o próprio governo.

De acordo com Baiocchi (2003b), o OP de Porto Alegre pode ser visto como uma estratégia de negociação de demandas e de legitimação das plataformas da população como um todo, tendo em vista a solução de conflitos. Já para Márcia Ribeiro Dias (2000), o OP de Porto Alegre foi uma forma de o Executivo sobrepor-se ao Legislativo. Segundo a autora, o OP conta com uma autonomia precária, e suas decisões não são soberanas, mas os vereadores as legitimam no momento em que se sentem constrangidos ao emendarem as propostas orçamentárias apresentadas pelo Executivo, com o aval do OP, renunciando ao seu poder de veto. Da mesma forma, o Executivo também legitima esse processo, na medida em que ele faz parte do projeto político do partido no governo.

A aliança entre o PT e os agentes do OP, na capital do Rio Grande do Sul, inaugurou um novo ciclo virtuoso para essa agremiação política, a qual

\footnotetext{
${ }^{18}$ Segundo Couto (1998, p. 65), a barganha alocativa consistiu em uma estratégia de negociação e adaptação, dentro de um programa mais amplo de ação governamental, das emendas de vereadores, visando ao atendimento das demandas de suas bases, em um contexto de necessidades mais localizadas. Esse processo se estendeu a partir da destinação de recursos próprios e de operações de créditos para o custeio de grandes obras viárias.
} 
conseguiu equilibrar muitos dos problemas anteriormente enfrentados pelas primeiras administrações do partido e, ao mesmo tempo, rompeu com a tradição predominante de gestões municipais sem canais institucionais de participação, obtendo êxito tanto na execução de políticas participativas quanto na sua proposta de inversão de prioridades, tornando-se um modelo a ser seguido por outras administrações petistas.

Ao comparar as experiências petistas, nas capitais gaúcha e paulista, para além das diferenças contextuais, podemos observar que a primeira obteve sucesso em controlar os entraves causados pelo Legislativo, bem como em administrar o excesso de demandas da população como um todo e da sua própria base de suporte, frente à disponibilidade de recursos existentes; e a última viveu uma situação de conflito constante entre os diversos atores locais até abrir espaço para a negociação com as outras forças políticas do município. Enquanto a administração gaúcha adotou o OP como ferramenta de planejamento, gestão e solução de conflitos, o governo do município de São Paulo adotou, embora tardiamente, uma estratégia de negociação com diferentes forças políticas. Enquanto a gestão de Porto Alegre expandiu a participação popular, a administração Erundina iniciou um processo que teve que ser deixado de lado em razão dos inúmeros conflitos e dos problemas a serem resolvidos. Enquanto o governo da capital gaúcha ganhou a eleição por quatro mandatos consecutivos e pôde dar continuidade ao processo participativo, o PT não se reelegeu no município de São Paulo nas quatro gestões seguintes ${ }^{19}$.

Dentro dessa perspectiva, o aprendizado de ambas as experiências demonstrou que administrações petistas reconheceram que devem encontrar caminhos para negociar com suas bases e com o Legislativo, enquanto desempenham uma governabilidade efetiva. Nesse sentido, o legado produzido por esses dois governos inaugurou um novo ciclo virtuoso para essa legenda, permitindo a continuidade e o aprofundamento daquilo que ficou amplamente conhecido como o "modo petista de governar", o qual pode ser resumido em quatro princípios básicos: a democratização do modo de governar mediante controle social do orçamento; a participação popular;

\footnotetext{
${ }^{19}$ No caso de São Paulo, o PT voltou a governar o município em dois períodos: a administração Marta Suplicy (2001-2004) e a atual gestão do prefeito Fernando Haddad (desde 2013). Em Porto Alegre, desde 2005, outros partidos se revezaram no poder: PPS (2005-2008), PMDB (2009-2010) e PDT (2010 até hoje).
} 
a inversão de prioridades e a transparência governamental ${ }^{20}$.

O OP de Porto Alegre foi uma tradução prática dessas novas ideias na medida em que incorporava os principais elementos dessa insurgente concepção de governo petista, demonstrando, acima de tudo, que o PT conseguia governar bem e com o apoio da população.

Embora o PT tenha intensificado a adoção de espaços participativos no nível municipal ${ }^{21}$, o OP tornou-se a "marca registrada do partido", visto que, a partir de 1993, as campanhas, as administrações e os encontros subsequentes evidenciaram a questão da participação popular, e a implantação do OP apareceu como uma das principais plataformas políticas do partido.

Da mesma maneira, verifica-se um crescimento notável da inserção dessa legenda na esfera municipal ao longo dos anos 1990 de tal forma que, no início dos anos 2000, o PT administrava 187 municípios, ou seja, 17,5\% da população brasileira. Como nota Baiocchi (2003b), embora o PT tenha crescido ao longo das disputas eleitorais (refere-se aos anos 1990 e início dos anos 2000), devido às experiências participativas bem-sucedidas de governos locais ${ }^{22}$, o partido continuou a sofrer derrotas e a vivenciar conflitos em virtude das disputas internas e das dificuldades de negociar com grupos políticos dominantes, entre outros fatores.

\section{A difusão e 0 aparente declínio do OP nos municípios brasileiros ${ }^{23}$}

O OP de Porto Alegre foi reconhecido pela ONU (Organização das Nações Unidas), em 1996, na Conferência de Istambul, Habitat II, como uma das 40

\footnotetext{
${ }^{20} \mathrm{O}$ conceito de aprendizado desenvolvido comporta duas dimensões: 1 . aprendizado quanto às composições políticas (alianças políticas) e 2. aprendizado técnico (administrativo).

${ }^{21}$ É importante lembrar que experiências participativas foram desenvolvidas em outros períodos da história brasileira, especialmente durante o processo de democratização do país (ver, por exemplo, COSTA, 1997). Além disso, a Constituição de 1988 definiu as bases para o novo arranjo federativo com transferências de funções para Estados e municípios e incorporou uma série de reivindicações dos movimentos sociais, possibilitando a construção de novas instituições democráticas em diferentes níveis de governo, como os conselhos de políticas públicas, os conselhos gestores e os OPs.

${ }^{22} \mathrm{O}$ autor cita, além do OP, o Projeto de Urbanização da Favela de Belo Horizonte (MG), os Programas de AIDS e de saúde mental de Santos (SP), entre outros.

${ }^{23}$ A esfera estadual não será abordada neste artigo, pois o OP e o PT foram mais promissores no nível municipal.
} 
melhores práticas de governo do mundo, o que intensificou a sua difusão para outros partidos, níveis de governos ${ }^{24}$ e países $^{25}$. Além disso, observa-se o crescimento dos debates técnico e acadêmico e das novas redes que se formaram em prol da democracia participativa ${ }^{26}$.

Embora não se tenha informações precisas sobre o universo desses novos arranjos participativos, logo após a primeira gestão petista que inaugurou essa prática, foram produzidos dados confiáveis para o período entre 1997 e 2000, os quais apontavam cerca de 140 municípios brasileiros com formas participativas de gestão orçamentária (RIBEIRO; GRAZIA, 2003). Entre os municípios que declararam realizar o OP, foram obtidas informações de 103 casos, dos quais $50 \%$ eram produtos de governos petistas.

Em um estudo mais recente, Avritzer (2006, p.623) aponta que o OP, em 2005, alcançou 170 cidades brasileiras. Segundo o autor, o grosso dos municípios que instituiu o OP, nesse período, diferentemente da experiência de Porto Alegre, era de pequeno a médio porte, tinha fraca tradição associativa, estava centrado nas regiões Sul e Sudeste do país e, assim como as informações da pesquisa anterior, quase metade desses novos experimentos estava ligada ao PT, enquanto a outra parte estava vinculada a outros partidos.

Paolo Spada (2014), em uma tentativa inédita de investigação estatística para adoção e abandono de inovações democráticas, identifica instâncias de OP, nas médias e grandes cidades brasileiras, entre 1989 e 2012. O autor apresenta os seguintes dados, a partir do Brazilian Participatory Budgeting Census (SPADA, 2012 apud SPADA, 2014, p.14), referentes ao número de cidades (com mais de 50.000 habitantes) que adotaram o OP, nos períodos

\footnotetext{
${ }^{24}$ Por exemplo, no Distrito Federal, na gestão Cristóvão Buarque, ainda no PT, 1994-1998; no Amapá, na gestão João Capibaribe, PSB, 1995-1998, reeleito para o período 1999-2002; no Rio Grande do Sul, na gestão Olívio Dutra, PT, 1999-2002; no Acre, na gestão Jorge Viana, PT, 19992002; no Mato Grosso do Sul, na gestão "Zeca do PT", 1999-2002 (segundo notícia da Folha de São Paulo, em 05/11/2001, o OP não teve continuidade); no Rio de Janeiro, na gestão Antony Garotinho, PDT (o qual foi eleito em coligação com o PT, que detinha o cargo de vicegovernadora, Benedita da Silva, mantida até 2000); em Minas Gerais, gestão Itamar Franco, PMDB, 1999-2002 (o qual recebeu apoio do PT de Minas Gerais na disputa pelo segundo turno da eleição, em 1998, em troca, o partido assumiu a Secretaria de Planejamento desde o início da gestão, ficando incumbido de realizar o OP no Estado).

${ }^{25}$ Os municípios pioneiros que adotaram o OP fora do Brasil foram: San-Denis (França), Rosário (Argentina), Montevidéu (Uruguai), Barcelona (Espanha), Bruxelas (Bélgica), entre outros.

${ }^{26}$ Pires e Martins (2011) realizaram uma pesquisa no Banco de Teses da CAPES e encontraram 48 teses e 236 dissertações (total de 284), entre 2000 e 2009, que tratam do OP.
} 
indicados: 1989-1992: 11; 1993-1996: 29; 1997-2000: 62; 2001-2004: 129; 2005-2008- 119; 2009-2012- 99. Entre outras informações relevantes, o autor aponta, na mesma pesquisa, o quantitativo de cidades que abandonaram o OP: 1993-1996: 4; 1997-2000:12; 2001-2004: 23; 2005-2008: 64; 2009-2012: 66 (SPADA, 2014, p.14). De acordo com os dados apresentados, observa-se que a taxa de abandono lentamente sobe e ultrapassa a taxa de adoção depois de 2004. Segundo o autor [SPADA, 2014, p.13-14 (tradução da autora)], "assumindo que a taxa de abandono permaneça constante, enquanto o número de adoções continua a declinar até a atual taxa, o OP desapareceria em 10 anos".

No entanto, em contraposição aos dados apresentados por Spada (2014) que englobam as cidades com mais de 50.000 habitantes, a última pesquisa quantitativa realizada pela Rede Brasileira de Orçamento Participativo (2013) distinguiu 353 experiências ou programas de OP no Brasil, sendo 14 na região Norte, 79 no Nordeste, 09 no Centro-Oeste, 151 no Sudeste e 100 espalhadas pelo Sul do país ${ }^{27}$. Esses dados sugerem que o número de OP, no Brasil, não está diminuindo (se compararmos com os dados para a totalidade do território nacional, por exemplo, as informações referentes ao período 1997 e 2000 levantadas por Ribeiro e Grazia (2003), embora haja uma aparente redução no ritmo de casos realizados no estado de São Paulo, por exemplo, como argumenta Spada $(2014)^{28}$.

Dentro dessa perspectiva, Pires e Martins (2011) notam que há uma dificuldade em quantificar as experiências de OP no Brasil e no mundo. Os autores contrastam as informações apresentadas por Ribeiro e Grazia $(2003)^{29}$, Cabannes $(2005)^{30}$ e Wampler (s/d) ${ }^{31}$, e colocam como uma das maiores dificuldades a própria disseminação do OP (nos anos 1990), que

\footnotetext{
27 Pesquisa disponível em: http://prezi.com/cuu_322j8egm/pesquisa-cidades-no-brasil-quepossuem-op/. Acesso em março de 2014.

${ }^{28}$ Segundo a Rede Brasileira de OP, em 2013, o estado de São Paulo registrou 42 experiências de OP. Se compararmos com os dados existentes para os períodos de 1997-2000: 23 casos (RIBEIRO; GRAZIA, 2003) e 2001-2004: 40 casos (SERAFIM; TEIXEIRA, 2008), observa-se que não houve um crescimento significativo da adoção do OP após 2004.

${ }^{29}$ 1989-1992: 12 experiências; 1996-1996: 36 experiências; 1997-2000: 140 experiências (PIRES; MARTINS, 2011, p. 101).

${ }^{30}$ Avalia a existência de 250 casos de OP, no mundo, em 2003 (PIRES; MARTINS, 2011, p.101).

${ }^{31}$ 1989-1992: 13 casos; 1993-1996: 52 casos; 1997-2000: 130 casos; 2001-2004: 177 casos (PIRES; MARTINS, 2011, p.101).
} 
levou inúmeros políticos, de diferentes partidos, a levantar a bandeira do OP, mas nem sempre realizar uma verdadeira mudança nos procedimentos orçamentários.

Os autores sublinham, com base em informações levantadas nos estudos de Balcão e Maranhão (2004 apud PIRES; MARTINS, 2011) e Serafim e Teixeira (2006) sobre as experiências desenvolvidas no estado de São Paulo ${ }^{32}$, e de Borba e Lüchmann (2007), a respeito dos casos de Santa Catarina ${ }^{33}$, que "nos anos mais recentes, ocorreu, no Brasil, uma aparente redução no ritmo das experiências de OP (...)" (PIRES; MARTINS, 2011, p.102), corroborando mais uma vez a tese de Spada (2014).

Contudo, ao observarmos as experiências de OP, sob o rótulo do PT, o cenário é outro. Segundo Wampler (2008, p.14-15), entre 1989 e 1992, o PT administrava 9 das 10 cidades que adotaram o OP. Já entre 1993-1996, o PT governava 12 das 17 experiências (66\%). Portanto, ao longo do período (1989-1996), o PT governava 21 dos 27 municípios que instituíram o OP (78\%). Nesse sentido, o autor sublinha que, inicialmente, a instituição do OP estava mais associada ao $\mathrm{PT}^{34}$, mas esse quadro se alterou na medida em que dois terços dos governos municipais que adotaram o OP durante 1997-200 (68\%) e 2001-2004 (64\%) eram de outros partidos políticos. De acordo com essa abordagem, o que explica a implementação do OP por outros partidos são os benefícios eleitorais e governamentais que esses governos acumulam ao se associarem ao programa, que é conhecido por sua ênfase em justiça social, transparência e participação direta ${ }^{35}$ (WAMPLER, 2008, p. 32).

Portanto, apesar de o debate sobre a difusão do OP no Brasil, tanto em municípios administrados pelo PT como por outros partidos, ainda ser precoce e não oferecer respostas conclusivas sobre essa questão, pode-se assegurar que, a despeito de sua rápida difusão em municípios brasileiros

\footnotetext{
${ }^{32}$ Segundo Balcão e Maranhão (apud PIRES; MARTINS, 2011, p.102), no estado de São Paulo foram identificadas 23 experiências entre 1997 e 2000 e 40 casos no período subsequente (20012004). Em 2005, Serafim e Teixeira (2006 apud PIRES; MARTINS, 2011, p.102) encontraram 30 casos, sendo que 5 iniciaram em 2005 (ou seja, somente 25 casos novos).

${ }^{33}$ Nesse caso, Pires e Martins (2011, p. 102) ressaltam mais os problemas enfrentados pelo OP no estado de Santa Catarina (1993-1997, p.1; 1997-2000, p.7; 2001-2004, p.18).

${ }^{34}$ Segundo o autor (WAMPLER, 2008), todos os municípios administrados pelo PT, com mais de 100 mil habitantes, implementaram o OP entre 1989 e 2004.

${ }^{35}$ A adoção do OP por outros partidos ainda foi pouco explorada pela literatura. E é uma das questões que está sendo investigada no meu projeto de pós-doutorado (em andamento).
} 
(no final dos anos 1990 e início dos anos 2000), a expansão do OP percorreu deslocamentos distintos, inclusive entre os próprios grupos políticos aliados ao PT. Isso significa que essa experiência apresentou resultados variados: há casos de continuação, abandono e interrupção da realização do OP entre uma gestão e outra, separados por um ou mais períodos. No estado de São Paulo, por exemplo, foram implementadas 23 experiências de OP entre 1997-2000, sendo que 12 dessas iniciativas continuaram e 11 foram interrompidas na gestão seguinte. Contudo, 28 novas experiências foram instituídas entre 2001 e 2004, totalizando 40 casos nesse período (SERAFIM; TEIXEIRA, 2008).

A discussão sobre as condições de sucesso do $\mathrm{OP}^{36}$, nas últimas duas décadas, destacou três argumentos importantes: a "vontade política" do Executivo de implementá-la; a influência do "desenho institucional", observado por meio dos elementos organizacionais incorporados ao processo participativo, e a existência de uma "forte tradição associativa" local (LÜCHMANN, 2002; AVRITZER, 2003; WAMPLER, 2003; LÜCHMANN; BORBA, 2007). Em geral, a literatura associa essas variáveis combinadas com as características sociais e políticas próprias do universo estudado, incluindo, especialmente, a capacidade administrativa e financeira dos municípios para programar as deliberações do OP, as divergências no interior do Executivo, bem como as suas relações com o Legislativo. Mais recentemente, alguns autores ampliaram esse debate, por meio das discussões a respeito dos interesses políticos do Executivo, do Legislativo, dos partidos, das lideranças políticas locais ao redor dessa instituição participativa, assim como das diferentes arenas nas quais esses conflitos se desenvolvem (AVRITZER, 2009; DIAS, 2000; GOLDFRANK; SCHNEIDER, 2006; ROMÃO, 2011; SOUZA, 2010, 2011, 2012, 2013a; WAMPLER, 2008, 2011).

Souza (2011), por exemplo, demonstrou que as variações nos padrões de relações entre o Executivo, o Legislativo e os partidos contribuíram para explicar os diferentes deslocamentos do OP (contínuo, descontínuo e interrompido), em três experiências petistas do interior do estado de São Paulo - São Carlos, Rio Claro e Matão. Nos municípios analisados, diversamente do que aconteceu na capital gaúcha, onde o OP constituía uma novidade, os vereadores já orquestraram desde o início uma reação a

\footnotetext{
${ }^{36}$ A literatura brasileira sobre o OP, em sua maioria, trata como sucesso a longevidade dessa instituição participativa, e não a sua efetividade.
} 
essa proposta. Só para ilustrar, no caso de São Carlos, onde o OP continuou durante as três últimas gestões analisadas, houve uma reação dos vereadores de vários partidos, inclusive do $\mathrm{PT}$, ao $\mathrm{OP}$, que gerou um acordo entre o Executivo e o Legislativo, no qual cada vereador passou a ter uma quantidade de recursos para fazer sua emenda individual, independentemente de ser da situação ou da oposição.

Goldfrank e Schneider (2006), sob o mesmo prisma, verificam que a experiência de OP estadual, no governo do Rio Grande do Sul (1999-2002), provocou resistências e rupturas institucionais. Segundo os autores, o OP estadual não conseguiu legitimar as relações entre o Executivo e o Legislativo por meio da mobilização popular, apenas favoreceu investimentos nas regiões mais pobres, onde os aliados petistas se mobilizavam e conseguiam investimentos via OP.

Desse modo, verifica-se que, embora a implantação do OP, no nível municipal, tenha despontado como uma das principais plataformas políticas do PT (ao longo dos anos 1990 e início dos anos 2000), a sua repercussão não foi homogênea ao longo do tempo, evidenciando a existência de limites a essa aparente lógica transformativa. No contexto político institucional, cabe destacar que as relações petistas com o Legislativo e a composição das outras forças políticas dentro do governo, as quais são indispensáveis à lógica governamental, confrontaram os velhos desafios de negociar barganhas políticas com essa nova instância participativa (GOLDFRANK; SCHNEIDER, 2006; SOUZA, 2011). Ao mesmo tempo, observa-se um crescimento contínuo dos municípios administrados pelo PT até os dias de hoje, os quais em sua maioria não adotaram o $\mathrm{OP}^{37}$.

\section{A conquista do governo federal e os possiveis impactos no OP}

Em 2002, há uma ruptura decisiva com os programas políticos petistas anteriores, a qual culminou com a vitória de Luís Inácio Lula da Silva nas eleições presidenciais.

\footnotetext{
${ }^{37}$ Em 1988, o PT venceu em 38 municípios; em 1996 foram 111 prefeituras conquistadas; em 2000 esse quantitativo aumenta para 187 cidades; em 2004 o mesmo indicador sobe para 383; em 2008 o número de prefeitos petistas continua a crescer, totalizando 558 cidades; e em 2012 o PT alcança 635 municípios. Das 635 prefeituras administradas pelo PT atualmente, 199 encontramse na região Sudeste, 187 no Nordeste e 158 no Sul do país (ABRAMO; TSE).
} 
Antes disso, observa-se uma mudança gradual do discurso petista, especialmente no que se refere à questão da participação popular, nas campanhas eleitorais presidenciais entre 1989, 1994 e 1998. Em 1989, o discurso da campanha foi desenvolvimentista, nacionalista e estatizante, além da ênfase nas questões sociais (AZEVEDO, 2009, p. 230) ${ }^{38}$. Em 1994, "o PT entra nas eleições denunciando o caráter eleitoreiro do Plano Real e apontando seu fracasso" (AZEVEDO, 2009, p. 230). O programa de governo intitulado "Uma revolução democrática no Brasil", aprovado no "9॰ Encontro Nacional", enfatizou a ampliação dos canais de participação e colocou a implantação do OP em nível nacional como um dos principais desafios do governo ${ }^{39}$. Já em 1998, o PT ainda com uma coalizão limitada ao campo da esquerda, mas já aberto à ampliação, entrou na disputa com um programa político mais aberto, voltado para o centro político, e com uma campanha orientada por pesquisa e marketing eleitoral e produzida de forma profissional (AZEVEDO, 2009, p. 230) ${ }^{40}$.

A campanha vitoriosa de 2002 denominada "Um Brasil para todos" rompeu definitivamente com as anteriores. O PT foi capaz de ampliar a sua coalizão eleitoral em direção ao centro político ao se aliar com o PL, o qual indicou o empresário José de Alencar à vice-presidência. A plataforma eleitoral foi marcada pela "Carta aos brasileiros", na qual o presidente Lula se comprometeu com a política de estabilidade monetária e fiscal vigentes durante o governo Fernando Henrique Cardoso. Além disso, a campanha foi estruturada num tom moderado e agradável ("Lulinha paz e amor") por um dos maiores fenômenos do marketing político (AZEVEDO, 2009, p. 232). Em relação à participação popular, embora o PT tenha colocado a ampliação da participação popular nas políticas setoriais e na gestão orçamentária no seu programa de governo, a sua ênfase durante a campanha foi a questão da estabilidade econômica. A implantação do OP, diferentemente dos programas políticos anteriores, foi vista de forma cautelosa, como um "desafio de peso" a ser enfrentado, em conjunto com a população, devido às

\footnotetext{
${ }^{38}$ Nesse mesmo ano, Lula teve $47 \%$ dos votos no $2^{\circ}$ turno das eleições presidenciais. Em 1990, o PT elegeu 35 membros para o Congresso Nacional e seu primeiro senador.

${ }^{39}$ Nessa eleição, Lula teve $27 \%$ dos votos no $2^{\circ}$ turno, e o seu partido ainda elegeu 2 governadores, 4 senadores e 50 cadeiras no Congresso Nacional.

${ }^{40} \mathrm{Em}$ 1998, Lula teve $32 \%$ dos votos no $1^{\circ}$ turno das eleições presidenciais. O PT elegeu 3 governadores, 7 senadores e 59 deputados no Congresso Nacional.
} 
dimensões geográficas e aos desenhos das políticas ${ }^{41}$.

Em 2005 explodiu o escândalo do mensalão, no qual o PT e outros partidos políticos foram acusados de um esquema de compra de votos parlamentares. Em 2006, o respectivo escândalo foi o principal tema da campanha eleitoral da oposição. O PT, por sua vez, desenvolveu uma agenda de campanha centrada basicamente no desempenho econômico e social do governo, evitando o debate acerca do tema (AZEVEDO, 2009, p.235). A questão da participação popular foi colocada de forma mais regulada, como forma de aprimoramento da democracia representativa, através da criação de espaços públicos que permitirão a geração de novos direitos e a efetiva participação da população, sem fazer referência alguma ao OP.

Embora o OP não tenha sido adotado no governo federal, verifica-se que novas instituições participativas foram criadas e reformadas no governo Lula ${ }^{42}$. Faria (2009) destaca a criação do Conselho de Desenvolvimento Econômico e Social (CDES), o qual chegou a promover encontros regionais para a elaboração do PPA (2004-2007). Entretanto, esse Conselho foi considerado limitado em relação à participação restrita a algumas organizações da sociedade civil e ao seu papel consultivo. Além disso, as negociações em torno da concretização do PPA (2008-2011) foram interrompidas para implantar o PAC (Programa de Aceleração de Crescimento), carros-chefes da política de desenvolvimento do segundo mandato presidencial (FARIA, 2009). A autora define o "método participativo" do governo Lula como um conjunto de regras e/ou procedimentos para regularizar o diálogo entre as organizações da sociedade civil e o governo, o qual está inserido num contexto mais complexo. O governo também instituiu a Secretaria Nacional de Articulação Social (SNAS), vinculada à Secretaria da Presidência, a qual busca integrar as organizações da sociedade civil.

Como poderíamos explicar, a um só tempo, o declínio do OP no interior das plataformas políticas petistas e o crescimento institucional do PT?

\footnotetext{
${ }^{41}$ Nessa eleição, Lula venceu no $2^{\circ}$ turno com $61,39 \%$ dos votos. O PT elegeu três governadores, 10 senadores e 91 deputados federais ( $57 \%$ a mais que em 1998).

${ }^{42}$ Foram realizadas 73 Conferências Nacionais Temáticas para debater políticas públicas, envolvendo, em seus vários níveis, cerca de 5 milhões de pessoas. Essas Conferências representaram $64 \%$ do total desses encontros (114) realizados no Brasil nos últimos 60 anos. Além disso, dos 61 Conselhos Nacionais de Políticas Públicas com participação popular existentes, 33 foram criados, ou reformados (18), ou democratizados (15) nos governos Lula (MATEOS, 2011).
} 
Ao examinarmos o modelo originário do partido, observamos que as questões da participação e da distribuição de recursos, tônicas do OP, estavam presentes em sua ideologia através da ideia de "socialismo democrático". No entanto, o programa político inicial do partido tinha uma forte conotação classista, restringindo a mensagem partidária a uma pequena parcela do eleitorado. Assim, o OP, num primeiro momento, pode ser pensado como fruto do programa político originário do PT que foi amadurecendo, tendo em vista os dilemas enfrentados por essa legenda e as estratégias utilizadas para conquista de espaço institucional. Nesse sentido, o OP colonizou o PT quando se tornou a tradução prática do "modo petista de governar", começando a ser adotado na maior parte das administrações petistas. Contudo, o PT vai mudando suas estratégias político-eleitorais e político-institucionais, quando alcança a esfera de governo federal, e a questão da participação, por sua vez, vai se adaptando a esse novo ambiente através de formatos participativos mais regulados e restritivos (por exemplo: que englobam as organizações da sociedade civil ao invés da população em geral).

De acordo com Ribeiro (2004), o deslocamento do PT de uma posição antissistêmica (numa perspectiva sartoriana) para uma mais próxima das forças políticas centristas, cujoápice se deu na campanha presidencial vitoriosa de 2002, iniciou-se internamente a partir de 1995 com o fortalecimento do "Campo Majoritário" ${ }^{4}$. Esse grupo dirigente enfatizou a democracia representativa, aceitando alianças voltadas ao centro do espectro políticopartidário brasileiro, como forma de atuação estratégica na luta por cargos executivos nas esferas nacionais e subnacionais (RIBEIRO, 2004, p.125). Segundo o autor (2004, p.125-126), a cúpula petista utilizou a separação entre disputa eleitoral e questão ideológica para justificar a construção de alianças que foram decisivas para a vitória eleitoral em 2002.

Dessa maneira, a divisão entre os ideais embrionários participacionistas e a competição eleitoral, concebidos pelo partido como inseparáveis até então, pode ser uma das hipóteses que contribui para explicar o progressivo abandono do OP, no interior do PT, a partir da conquista do governo federal.

\footnotetext{
${ }^{43}$ O Campo Majoritário é um conjunto de tendências que se consolida dentro do PT, dentre as quais se destaca a Articulação, formada a partir de 1995. Entre os políticos que compõem o Campo Majoritário, destacam-se: Ricardo Berzoini, José Dirceu, José Genoíno, Luiz Dulci, Marco Aurélio Garcia e o presidente Luís Inácio Lula da Silva.
} 
Spada (2014) apresenta duas importantes explicações para o declínio dessas experiências: a erupção de uma "policy bubble" (apud JONES et al., 2004) e a mudança nas estratégias do PT (apud HUNTER, 2008). Na última explicação, que mais se adapta aos propósitos deste artigo, o autor questiona o porquê de essa legenda ter investido mais no OP nos anos 1990 e, após 2004, ter deixado de fazê-lo. Nos anos 1990, o autor utiliza o argumento de Hunter (2008) para formular uma das suas hipóteses. Esse argumento aponta que a corrente do PT controlada por Lula promoveu inovações governamentais municipais como um caminho para delimitar uma marca de "boa governança" do partido. Contudo, esse mecanismo vertical de influência deixou de existir quando Lula venceu as eleições presidenciais, em 2002, abrindo a possibilidade de novas políticas que podem substituir o OP, em termos de benefícios eleitorais ${ }^{44}$ (policy bubble). Como não é possível verificar isso, o autor lança outras hipóteses interessantes, entre as quais a vulnerabilidade política dos governos das cidades, que é medida através da proporção dos votos sobre o partido do prefeito e o controle do prefeito sobre o Legislativo (porcentagem de cadeiras do partido do prefeito no Legislativo). O autor (2014, p.39) verifica que onde há forte vulnerabilidade do prefeito (em termos de seus próprios votos), também há maior probabilidade de adotar e continuar o programa. Por conseguinte, quando prefeitos são menos vulneráveis em termos de cadeiras no legislativo, o OP tem mais chance de continuar.

Segundo o autor, a oposição no Legislativo leva ao abandono do OP, mas não influencia sua adoção. Portanto, os resultados corroboram com os argumentos do estudo de Goldfrank e Scheneider (2006), no caso do OP estadual, e de Souza (2011), no caso das experiências de OP analisadas no interior do estado de São Paulo, já descritos na seção anterior.

\footnotetext{
${ }^{44} \mathrm{O}$ autor aponta a ampliação do Bolsa Família em 2003, a introdução do Minha Casa Minha Vida em 2009 e a ampliação dos Conselhos e Conferências como exemplos de políticas que podem substituir alguns dos efeitos do OP sem impor algum custo no nível municipal (SPADA, 2014, p. 27). Entretanto, ele deixa de citar o Programa de Aceleração de Crescimento (PAC), carro-chefe do segundo mandato de Lula, o qual incide diretamente em obras de infraestrutura e necessita de contrapartidas dos municípios (no mínimo de 20\%) para sua implementação, impactando diretamente no orçamento para investimento municipal e, portanto, no OP.
} 


\section{Considerações finais}

OPT entrou em cena no sistema político brasileiro com seu ideal de "socialismo democrático" e uma postura fortemente influenciada pelo novo sindicalismo, que refletia o discurso demasiadamente classista dessa legenda no início da sua trajetória política, a qual coincide com o momento histórico da retomada das eleições diretas. Esse ambiente contribuiu para o partido reestruturar suas relações internas, com suas bases de suporte e com a sociedade em geral. O OP foi um amadurecimento das concepções embrionárias do partido, a qual se tornou fundamental tanto para essa agremiação política como para as primeiras experiências de governo municipal.

Sendo assim, as experiências bem-sucedidas de governos municipais que praticaram OP parecem ter contribuído para a inserção do partido nas esferas estatais ao longo dos anos 1990 e início dos anos 2000. Entretanto, a existência de limites a essa aparente lógica transformativa mostrou-se clara no contexto político ao longo do tempo. Por exemplo, a experiência de OP estadual, no Rio Grande do Sul (1999-2002), que provocou uma reação contrária do Legislativo, além de intervenção do Judiciário e da mídia que o rotularam de ilegal, distinguindo a sua natureza partidária (GOLDFRANK; SCHNEIDER, 2006). Nesse sentido, o PT a partir de 1995, com o fortalecimento do Campo Majoritário, ampliou sua política de alianças e, consequentemente, as políticas participativas embrionárias, tais como o OP, acabaram arrefecendose nos programas de governos petistas.

Nota-se que, à medida que o PT se consolida como um dos mais importantes partidos da história política brasileira, o OP está percorrendo o caminho inverso no interior das principais plataformas políticas petistas devido às mudanças nas estratégias políticas dessa legenda para a conquista de espaço institucional.

Nesse sentido, conclui-se que o PT não abandonou as políticas participativas no governo federal, mas imprimiu a elas contornos mais restritivos, o que de certa forma exclui o OP como uma forma de aprimoramento da democracia representativa, uma vez que essa legenda passou a priorizar a questão da estabilidade econômica e as coalizões governamentais como estratégias políticas. O reflexo disso pode ser observado nos novos espaços participativos que foram criados e reformados, assim como um conjunto de regras e/ou procedimentos para regularizar o diálogo entre as organizações da sociedade civil e o governo federal se multiplicou nos últimos governos federais petistas. 
Em resumo, conforme procuramos demonstrar neste artigo, o OP foi uma forma de aprendizado para o PT de política (politics) e das políticas (policies) do local para o nacional.

\section{Referências}

ABRAM0, Fundação Perseu.

(2010). Resoluções de Encontros e Congressos:

Partido dos Trabalhadores: 1979-1998". Disponível em: http://csbh.fpabramo.org. br/. Acesso em 10 de junho de 2010.

AVRITZER, L.

(2009). Participatory Institutions in Democratic Brazil. Baltimore, Johns Hopkins University Press.

(2006). New Public Spheres in Brazil: Local Democracy and Deliberative Politics. International Journal of Urban and Regional Research, v. 30, n.3, p. 623-637.

(2003). 0 Orçamento Participativo e a teoria democrática: um balanço crítico. In: Leonardo Avritzer; Zander Navarro. (Org.); A inovação democrática no Brasil: o orçamento participativo. São Paulo: Cortez.

AZEVED0, Fernando Antônio.

(2009). 0 PT, a imprensa e as coberturas das eleições. In: Marco Antonio Villa; Vitor Amorim de Angelo (Org.); O Partido dos Trabalhadorese a política brasileira (1980-2006): uma história revisitada. São Carlos, SP: EdUFSCar.

BAIOCCHI, G.

(2003a). Radicals in Power. In: Gianpaolo Baiocchi (Ed.); Radicals in Power: The Worker's Party (PT) and Experiments in Urban Democracy in Brazil. London: Zed Books Ltd.

(2003b). The Long March Through Institutions: Lessons from the PT in Power. In: Gianpaolo Baiocchi (Ed.); Radicals in Power: The Worker's Party (PT) and Experiments in Urban Democracy in Brazil. London: Zed Books Ltd.
BITTAR, Jorge (0rg.).

(2003). Governos estaduais: desafios e avanços - reflexões e relatos de experiência petistas. São Paulo: Editora Fundação Perseu Abramo.

BORBA, Julian; LÜCHMANN, Ligia H.H. (Org.). (2007). Orçamento Participativo: análise das experiências desenvolvidas em Santa Catarina. Florianópolis: Insular.

COSTA, S.

(1997). Movimentos sociais, democratização e a construção de esferas públicas locais. Dados - Revista Brasileira de Ciências Sociais, v.12, n. 35, p.112-24.

COUTO, Claudio Gonçalves.

(2003). The Second Time Around: Marta Suplicy's PT Administration in São Paulo. In: Gianpaolo Baiocchi (Ed.); Radicals in Power: The Worker's Party (PT) and Experiments in Urban Democracy in Brazil. London: Zed Books Ltd.

(1998). Negociação, Decisão e Governo: Padrões Interativos na Relação Executivo-Legislativo e o Caso Paulistano. In: ANDRADE, R. C. (org). Processo de Governo no Município e no Estado: uma análise a partir de São Paulo. São Paulo: Editora da Universidade de São Paulo.

(1995). O desafio de ser governo: o PT na prefeitura de São Paulo (1989-1992). Rio de Janeiro: Paz e Terra.

DANIEL, Celso.

(1990). As administrações democráticas e populares em questão. Espaços \& Debates Revista de Estudos Regionais e Urbanos, ano $X, n^{\circ} 30$. 
DIAS, Márcia Ribeiro.

(2000). Na encruzilhada da teoria democrática: efeitos do Orçamento Participativo sobre a Câmara Municipal de Porto Alegre. Tese de doutorado apresentada ao Programa de Pósgraduação em Ciência Política do Instituto de Universitário de Pesquisas do Estado do Rio de Janeiro (UPERJ).

FARIA, Cláudia Feres.

(2009). Participação, Sociedade Civil e Governo Lula (2003-2006): Construindo uma Sinergia Positiva?. In: Marco Antonio Villa; Vitor Amorim Angelo (Orgs.); 0 Partido dos Trabalhadores e a política brasileira (19802006): uma história revisitada. São Carlos: EdUFSCar.

GENRO, Tarso.

(2000). Co-gestão: reforma democrática do Estado. In: Por uma nova esfera pública: a experiência do orçamento participativo. Petrópolis, RJ: Vozes.

(1997). Porto da Cidadania. Porto Alegre: Artes e Ofícios.

GOLDFRANK, Benjamin; SCHNEIDER, Aaron. (2006). Competitive Institution Building: the PT and Participatory Budgeting in Rio Grande do Sul. Latin American Politics \& Society, v. 48, n. 3, p.1-31.

KECK, Margareth E.

(1996). A lógica da diferença: o PT na constituição da democracia brasileira. São Paulo: Ática.

GURZA LAVALLE, Adrian.

(2011). Participação valor, utilidade, efeitos e causa. In: Roberto Rocha Coelho Pires (Org.);. Efetividade das instituições participativas no Brasil: estratégias de avaliação. Brasília: IPEA.

KOWARICK, Lúcio; SINGER, André.

(1993). A experiência do Partido dos Trabalhadores na Prefeitura de São Paulo. Revista Novos Estudos, n 53, p.195-216.
LEVI, M Margareth.

(1991). Uma Lógica da Mudança Institucional. Dados - Revista de Ciências Sociais, v. 34, n० 01, p.79-99.

LÜCHMANN, Lígia H. H.

(2002). Possibilidades e limites da democracia deliberativa: a experiência do Orçamento Participativo de Porto Alegre. Tese de doutorado apresentada ao Instituto de Filosofia e Ciências Humanas da Universidade Estadual de Campinas (Unicamp).

MAGALHÃES, Inês; BARRETO, Luiz; TREVAS, Vicente (Orgs.).

(1999). Governo e Cidadania: balanços e reflexões sobre o modo petista de governar. São Paulo: Fundação Perseu Abramo.

MATEOS, Simone Biehler.

(2011). A construção da democracia participativa. Desafios do Desenvolvimento. IPEA, ano 8, n. 65.

MENEGUELLO, Raquel.

(1998). Partido e Governo no Brasil Contemporâneo (1985-1997). Rio de Janeiro: Paz e Terra.

(1989). PT: a formação de um partido, 19791982. Rio de Janeiro: Paz e Terra.

NOVAES, Carlos Alberto Marques.

(1993). PT: dilemas da burocratização. Novos Estudos, no 35, p. 217-237.

PANEBIANCO, Ângelo.

(2005). Modelos de partido: Organização e poder nos partidos políticos. São Paulo: Martins Fontes.

PIRES, Valdemir.

(2001). Orçamento Participativo: o que é, para que serve, como se faz. São Paulo: Manole.

PIRES, Valdemir; MARTINS, Larissa de Jesus.

(2011). Orçamento Participativo (OP) após vinte anos de experiências no Brasil: mais qualidade na gestão orçamentária municipal? Revista Capital Científico, Guarapuava - PR, v. 9, n. 2. 
PONT, Raul.

(2000). Democracia Representativa e Democracia Participativa. In: Nilton Bueno Fisher; Jaqueline Moll (Orgs.); Por uma nova esfera pública: a experiência do orçamento participativo. Petrópolis, RJ: Vozes.

RIBEIR0, Ana Clara Torres; GRAZIA, Grazia de. (2003). Experiências de Orçamento Participativo no Brasil: período de 1997 a 2000. São Paulo: Vozes.

RIBEIRO, Pedro Floriano.

(2009). 0 PT, o Estado e a Sociedade (19892005). In: Marco Antonio Villa; Vitor Amorim Angelo (Orgs.); 0 Partido dos Trabalhadores e a política brasileira (1980-2006): uma história revisitada. São Carlos, SP: EdUFSCar.

RIBEIRO, Pedro Floriano.

(2008). Dos Sindicatos ao governo: a organização nacional do PT de 1980 a 2005. 2008. 301f. Tese de doutorado apresentada ao Programa de Pós-graduação em Ciência Política da Universidade Federal de São Carlos.

(2004). Um partido em mutação: a transformação do PT e seus reflexos sobre as campanhas presidenciais (1989, 2002). 2004. 184f. Dissertação de mestrado apresentada ao Programa de Pós-graduação em Ciências Sociais da Universidade Federal de São Carlos.

ROMÃO, W. M.

(2011). Conselheiros do Orçamento Participativo nas franjas da sociedade política. Lua Nova (Impresso), v. 84, p. 219-244.

SERAFIM, Lisandra; TEIXEIRA, Ana Cláudia. (2008). Balanço e desafios para a continuidade do OP - gestão 2005-2008. Disponível em: http://dc118.4shared.com/doc/y8ih6ssU/ preview.html. Acesso em 03 de junho de 2008.

SOUZA, Luciana A. M. de.

(2013a). Afinal, o que é 'vontade política'? Uma perspectiva a partir da comparação entre as variações dos resultados de experiências de Orçamento Participativo. Anais do $37^{\circ}$ Encontro Anual da Associação Nacional de
Pós-graduação em Ciências Sociais (ANPOCS). Minas Gerais, Águas de Lindóia.

(2013b). “Virada institucional": o debate sobre as instituições, os atores e os interesses políticos nas três gerações de estudos sobre Orçamento participativo. Paper apresentado no Encontro Internacional - UNESP: participação, democracia e políticas públicas. São Paulo, Araraquara, 23 a 25 de abril.

(2011). 0 Orçamento Participativo (OP) e a questão da institucionalização da participação popular ao longo da história do Partido dos Trabalhadores (PT). In: II Fórum de Pós-Graduação em Ciência Política. São Carlos - São Paulo. Disponível em http://www.forumcienciapolitica.com.br/ edicoesanteriores/2011/especific_files/ papers/GT7570.pdf . Acesso em: $11 \mathrm{em}$ outubro de 2014.

(2011). Orçamento Participativo e as novas dinâmicas políticas. Lua Nova, n. 84.

(2010). Do Local para o Nacional: o Orçamento Participativo e as novas práticas políticas petistas. Tese de doutorado apresentada ao Programa de Pós-graduação em Ciência Política da Universidade Federal de São Carlos.

SPADA, Paolo.

(2014). The Adoption and Abandonment of Democractic Innovations: Investigating the Rise and Decline of participatory Budgeting in Brazil. Latin American Studies Association (LASA).

TELLES, Helcimara de Souza.

(2009). 0 PT e as Eleições para a Câmara dos Deputados. In: Marco Antonio Villa; Vitor Amorim de Angelo (Orgs.); 0 Partido dos Trabalhadores e a política brasileira (19802006): uma história revisitada. São Carlos, SP: EdUFSCar.

WAMPLER, B.

(2010). Transformando o Estado e a sociedade civil por meio da expansão das comunidades política, associativa e de políticas públicas. In: Leonardo Avritzer (0rg.); A dinâmica da 
participação local no Brasil. São Paulo: Cortez, v. 3.

(2008). Does Participatory Budgeting Deepen the Quality of Democracy? Lessons from Brazil. Disponivel em http://www. internationalbudget.org/themes/PB/ Participatory Institutions.pdf. Acesso em 29 setembro de 2008.
(2003).Orçamento Participativo:umaexplicação para amplas variações nos resultados. In: Leonardo Avritzer; Zander Navarro (Org.); A inovação democrática no Brasil: o orçamento participativo. São Paulo: Cortez.

\section{Recebido em}

março de 2014

Aprovado em

abril de 2015 